\title{
BOND STRENGTH AND MORPHOLOGY OF ENAMEL USING SELF-ETCHING ADHESIVE SYSTEMS WITH DIFFERENT ACIDITIES
}

\author{
Sandra Kiss MOURA ${ }^{1}$, Alessandra REIS ${ }^{2}$, Arlete PELIZZARO ${ }^{3}$, Karen DAL-BIANCO ${ }^{3}$, Alessandro Dourado LOGUERCIO ${ }^{2}$, \\ Victor Elias ARANA-CHAVEZ ${ }^{4}$, Rosa Helena Miranda GRANDE ${ }^{4}$
}

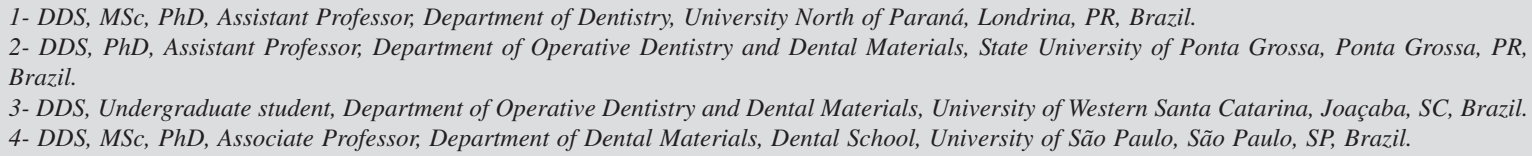

Corresponding address: Profa. Dra. Rosa Helena Miranda Grande - Faculdade de Odontologia - Universidade de São Paulo - Departamento de Materiais Dentários - Av. Lineu Prestes, 2227 - Cidade Universitária - 05508-000 - São Paulo - SP - Brasil - Phone/fax: +55-11-3091-7840 ramal 206 e-mail: grande@usp.br

Received: June 2, 2008 - Modification: August 31, 2008 - Accepted: October 7, 2008

\begin{abstract}
$O$

bjectives: To assess the bond strength and the morphology of enamel after application of self-etching adhesive systems with different acidities. The tested hypothesis was that the performance of the self-etching adhesive systems does not vary for the studied parameters. Material and methods: Composite resin (Filtek Z250) buildups were bonded to untreated (prophylaxis) and treated (burcut or SiC-paper) enamel surfaces of third molars after application of four self-etching and two etch-and-rinse adhesive systems ( $\mathrm{n}=6 /$ condition): Clearfil SE Bond (CSE); OptiBond Solo Plus Self-Etch (OP); AdheSe (AD); Tyrian Self Priming Etching (TY), Adper Scotchbond Multi-Purpose Plus (SBMP) and Adper Single Bond (SB). After storage in water $\left(24 \mathrm{~h} / 37^{\circ} \mathrm{C}\right)$, the bonded specimens were sectioned into sticks with $0.8 \mathrm{~mm}^{2}$ cross-sectional area and the microtensile bond strength was tested at a crosshead speed of $0.5 \mathrm{~mm} / \mathrm{min}$. The mean bond strength values (MPa) were subjected to two-way ANOVA and Tukey's test $(\alpha=0.05)$. The etching patterns of the adhesive systems were also observed with a scanning electron microscope. Results: The main factor adhesive system was statistically significant $(\mathrm{p}<0.05)$. The mean bond strength values (MPa) and standard deviations were: CSE $(20.5 \pm 3.5)$, OP (11.3 \pm 2.3$), \mathrm{AD}(11.2 \pm 2.8)$, TY (11.1 \pm 3.0$)$, SBMP (21.9 \pm 4.0$)$ and SB (24.9 \pm 3.0$)$. Different etching patterns were observed for the self-etching primers depending on the enamel treatment and the $\mathrm{pH}$ of the adhesive system. Conclusion: Although there is a tendency towards using adhesive systems with simplified application procedures, this may compromise the bonding performance of some systems to enamel, even when the prismless enamel is removed.
\end{abstract}

Key words: Enamel. Bonding. Adhesive systems. Morphology.

\section{INTRODUCTION}

The self-etching approach has been proposed in an effort to simplify the dentin/enamel bonding systems. These materials combine tooth surface etching and priming steps into one single procedure. The elimination of separate etching and rinsing steps simplified the bonding technique and has been responsible for the increased popularity of these systems in daily practice ${ }^{33}$.

Self-etching adhesive systems differ from etch-and-rinse adhesives in several aspects, such as the initial $\mathrm{pH}$, type of acidic monomer, number of bottles and steps, concentration of water and solvents, and the hydrophilicity of the bonding layer. They are classified into two- or one-step systems depending on the number of procedures required for bonding, as well as in mild, moderate and acidic systems depending on their initial $\mathrm{pH}^{31}$.

The clinical application of these systems would be even further promising if their performance were at least similar to that of three-step etch-and-rinse adhesive systems, which are considered clinically favorable on bonding to enamel and dentin ${ }^{23}$ because both substrates need to be hybridized in most clinical situations. As the $\mathrm{pH}$ of self-etching systems is not similar to that of phosphoric acid used in the etchand-rinse approach, increasing concern about their performance on intact enamel has been raised. In several clinical procedures enamel is slightly ground during a bevel or cut during cavity preparation, which provides a more receptive substrate for bonding ${ }^{13}$. However, there are cases such as bonding of orthodontic brackets or conservative and 
preventive restorative procedures, where bonding should be made on intact enamel. Therefore, it is clinically important to determine the performance of such systems on ground vs. unground enamel substrates.

Some studies have demonstrated that self-etching adhesives can provide resin-enamel bond strength values as high as those obtained by phosphoric acid treatment, as long as the bonding is performed on ground enamel ${ }^{13}$. However, other authors have not observed any difference on the performance of self etching systems when applied on ground and unground enamel ${ }^{10}$. One of the differences that might have accounted for the conflicting results of these two studies was the way enamel was prepared. While in the former study ${ }^{13}$ enamel was prepared with a high-speed diamond bur, silicon carbide paper was used the latter study ${ }^{10}$. It is likely that the use of high-speed diamond bur may expose deeper enamel surface than the use of silicon carbide paper. Based on that, we hypothesize that the kind of enamel preparation might affect the bond strength of selfetching adhesive systems to enamel. Therefore, the purpose of this study was to evaluate the bond strength and etching pattern of enamel after application of two-step self-etching and etch-and-rinse adhesive systems to unground, burprepared and silicon carbide paper-treated enamel. The null hypothesis tested was that the bonding performance of the self-etching adhesives does not vary for the studied parameters.

\section{MATERIAL AND METHODS}

This study was approved by the Institutional Review Board of the Dental School (Faculty of Dentistry, University of São Paulo, FOUSP) under protocol number 208/03.

\section{Microtensile Bond Strength}

Fifty-four extracted third molars were obtained and immersed in $0.5 \%$ chloramine at $4^{\circ} \mathrm{C}$ during 7 days ${ }^{5}$ before the beginning of the laboratorial setting. The teeth were then sectioned in a mesiodistal direction in order to obtain tooth halves that were randomly distributed to each experimental condition.

The obtained buccal and lingual surfaces were cleaned with a pumice and water and examined under a stereomicroscope to ensure that they were free of surface cracks, decalcification or any sign of previous grinding. After that, the bonding area was demarcated to outline the flattest area. The occlusal third of the buccal and lingual surfaces were usually outside the bonding area due to their inclination. The tooth halves were then randomly assigned to 3 groups according to the type of enamel surface preparation: Group 1: pumice prophylaxis (no grinding was done); Group 2: after prophylaxis, a wheel medium-grit diamond bur (\# 4142, particle size ca $100 \mathrm{~mm}$, KG Sorensen, Barueri, SP, Brazil) was applied on enamel surface using a high-speed handpiece with water coolant. This procedure created 0.5-mm-deep grooves on the surface, which was then flattened with a tapered round-end fine-grit diamond bur (\# 4138, particle size ca 46 mm, KG Sorensen); Group 3: after prophylaxis, the enamel was ground with a 60-grit silicon carbide paper $^{14,30}$ under water cooling for $60 \mathrm{~s}$.

Each group was further divided into six subgroups according to the adhesive system used. Six tooth halves were assigned to each condition. Four two-step self-etching adhesive systems were used: a mild system $(\mathrm{pH}=2.0)$ (Clearfil SE Bond - CSE; Kuraray Medical Inc, Tokyo, Japan), two intermediate strong systems $(\mathrm{pH}=1.5)$ (OptiBond Solo Plus Self-Etch Primer - OP; Kerr Co, Orange, CA, USA and AdheSe - AD; Ivoclar Vivadent, Schaan, Liechtenstein) and an acidic system $(\mathrm{pH}<1)($ Tyrian Self Priming Etchant - TY; BISCO Inc, Schaumburg, IL, USA). The $\mathrm{pH}$ of each system is provided by their manufacturers and have also been measured in a previous study ${ }^{14}$. Two and three-step etch-and-rinse adhesive systems - Adper Scotchbond Multi-Purpose Plus - SBMP and Adper Single Bond - SB (3M/ESPE, St Paul, MN, USA), respectively - were used as controls. All adhesive systems were applied under controlled environmental conditions $\left(24^{\circ} \mathrm{C} / 60 \%\right.$ relative humidity) by a single operator, following the bonding protocols summarized in Figure 1.

Special care was taken to ensure that the enamel surfaces were adequately coated by monomer after solvent evaporation. In the event matte enamel was observed, an additional coat of adhesive was applied to produce shiny surfaces prior to light-curing with a VIP unit $\left(600 \mathrm{~mW} / \mathrm{cm}^{2}\right.$, BISCO Inc, Schaumburg, IL, USA). Next, a 3-mm-high composite resin (Filtek Z250, 3M/ESPE) block was incrementally built up on the treated enamel surface and each 1-mm thick increment was light cured individually. After storage in distilled water at $37^{\circ} \mathrm{C}$ for $24 \mathrm{~h}$, the specimens were sectioned longitudinally in both " $x$ " and "y" directions across the bonded interface with a diamond saw in a Labcut 1010 machine (Extec; Enfield, CT, USA) to obtain approximately 5-7 bonded sticks per tooth with a cross-sectional area of about $0.8 \mathrm{~mm}^{2}$.

The number of prematurely debonded sticks (PD) per tooth during specimen preparation was recorded. Each stick was examined with a stereomicroscope $(\mathrm{x} 10)$ in order to check the inclination of the bonding interfaces in the four sides of each stick. Sticks with bent bonding interfaces were not tested in tension. The cross-sectional area of each stick was measured with a digital caliper accurate to the nearest $0.01 \mathrm{~mm}$ (Absolute, Mitutoyo, Tokyo, Japan) and recorded for calculation of the bond strength. Each stick was then individually fixed to a custom-made testing jig and tested in microtensile strength to failure in a universal testing machine (Emic, São José dos Pinhais, PR, Brazil) running at a crosshead speed of $0.5 \mathrm{~mm} / \mathrm{min}$. The bond failure modes were evaluated at $\mathrm{x} 400$ with light stereomicroscope (HMV2, Shimadzu, Tokyo, Japan) and classified as cohesive (failure exclusively within enamel or composite resin) and adhesive/mixed (failure at resin/enamel interface or mixed with cohesive failure of the neighboring substrates).

A bond strength index (BSI) was calculated for each tooth half ${ }^{24,25}$. The BS index is a weighted mean assuming the relative contribution of the possible mode of failures, 


\begin{tabular}{|c|c|c|}
\hline $\begin{array}{l}\text { Adhesive system } \\
\text { (Batch number) }\end{array}$ & Composition & Instructions for use \\
\hline $\begin{array}{c}\text { Clearfil SE Bond } \\
(00176 \mathrm{~A} ; 001185 \mathrm{~A})\end{array}$ & $\begin{array}{c}\text { Primer - water, MDP, HEMA, } \\
\text { camphoroquinone, hydrophilic } \\
\text { dimethacrylate, } \\
\text { Adhesive - MDP, Bis-GMA, HEMA, } \\
\text { camphoroquinone, hydrophobic } \\
\text { dimethacrylate, N,N-diethanol p-toluidine } \\
\text { bond, colloidal silica }\end{array}$ & $\begin{array}{l}\text { 1- Application of two coats of the primer with } \\
\text { slight agitation ( } 20 \mathrm{~s}) ; 2 \text { - Air-drying (10 s at } 20 \\
\mathrm{~cm}) ; \mathbf{3} \text { - Application of one coat of the adhesive } \\
(15 \mathrm{~s}) ; 4 \text { - Air-drying }(10 \mathrm{~s} \text { at } 20 \mathrm{~cm}) ; 5 \text { - Light- } \\
\text { activation }\left(10 \mathrm{~s}-600 \mathrm{~mW} / \mathrm{cm}^{2}\right)\end{array}$ \\
\hline $\begin{array}{l}\text { OptiBond SOLO Self } \\
\text { Etching + Solo Plus } \\
(205187 ; \text { 203D20) }\end{array}$ & $\begin{array}{c}\text { Primer - alkyl dimethacrylate resins, } \\
\text { barium aluminoborosilicate glass, fumed } \\
\text { silica (silicon dioxide), sodium } \\
\text { hexafluorosilicate and ethyl alcohol; } \\
\text { Adhesive - alkyl dimethacrylate resins } \\
(25-28 \%) \text {, ethyl alcohol, water, stabilizers } \\
\text { and activators }\end{array}$ & $\begin{array}{c}1 \text { - Application of } 1 \text { coat of the primer with slight } \\
\text { agitation }(15 \mathrm{~s}) ; \mathbf{2} \text { - Air-drying for } 10 \mathrm{~s} \text { at a } \\
\text { distance of } 20 \mathrm{~cm} ; 3 \text { - Application of } 1 \text { coat of the } \\
\text { adhesive ( } 15 \mathrm{~s} \text { with slight agitation); } 4 \text { - Air-drying } \\
\text { (10 s at } 20 \mathrm{~cm}) ; 5 \text { - Application of } 1 \text { coat of the } \\
\text { adhesive }(15 \mathrm{~s} \text { with slight agitation); } 6 \text { - Air-drying } \\
(10 \mathrm{~s} \text { at } 20 \mathrm{~cm}) ; 7 \text { - Light-activation ( } 20 \mathrm{~s}-600 \\
\left.\mathrm{~mW} / \mathrm{cm}^{2}\right)\end{array}$ \\
\hline $\begin{array}{c}\text { Adhe SE } \\
\text { (G03221; G02780) }\end{array}$ & $\begin{array}{l}\text { Primer - dimethacrylate, phosphonic } \\
\text { acid acrylate, initiators, stabilizers, water. } \\
\text { Adhesive - HEMA, BisGMA, GDMA, } \\
\text { silicon dioxide, initiators, stabilizers. }\end{array}$ & $\begin{array}{l}1 \text { - Application of } 1 \text { coat with slight agitation for } \\
15 \mathrm{~s} \text {. The primer should be left undisturbed for } \\
\text { more } 15 \mathrm{~s} ; \mathbf{2} \text { - Air-drying ( } 10 \mathrm{~s} \text { at } 20 \mathrm{~cm} \text { ) until the } \\
\text { mobile liquid film disappear; } 3 \text { - Application of } 1 \\
\text { coat of the adhesive without pooling; } 4 \text { - Light- } \\
\text { activation }\left(10 \mathrm{~s}-600 \mathrm{~mW} / \mathrm{cm}^{2}\right)\end{array}$ \\
\hline $\begin{array}{l}\text { Tyrian SPE+One Step } \\
\text { Plus } \\
(200002694 \\
\text { 200004295) }\end{array}$ & $\begin{array}{c}\text { Primer - 2-Acrylamido-2-methyl } \\
\text { propanesulfonic acid (2-15\%); Bis-GMA; } \\
\text { Ethanol (25-50\%) } \\
\text { Adhesive - Bis-GMA, BPDM, HEMA, } \\
\text { Glass Frit initiator and acetone }(40-70 \%)\end{array}$ & $\begin{array}{c}1 \text { - Mixture of Tyrian SPE (A and B) and } \\
\text { application of } 2 \text { coats with slight agitation (10 s); } \\
2 \text { - Air-drying (10 s at } 20 \mathrm{~cm}) ; 3 \text { - Application of } 2 \\
\text { consecutive coats of the adhesive, brushing for } \\
10 \mathrm{~s} \text { each; } 4 \text { - Air-drying }(10 \mathrm{~s} \text { at } 20 \mathrm{~cm}) ; 5 \text { - } \\
\text { Light-activation }\left(10 \mathrm{~s}-600 \mathrm{~mW} / \mathrm{cm}^{2}\right)\end{array}$ \\
\hline $\begin{array}{c}\text { Adper ScotchBond } \\
\text { Multi Purpose Plus } \\
\quad(3008 ; 7543)\end{array}$ & $\begin{array}{c}\text { 37\% phosphoric acid } \\
\text { Primer - aqueous solution of HEMA, } \\
\text { polyalkenoic acid copolymer (Vitrebond) } \\
\text { Adhesive - Bis-GMA, HEMA, } \\
\text { dimethacrylates and initiators. }\end{array}$ & $\begin{array}{l}1 \text { - Acid etching (15 s), rinsing (15 s) and Air- } \\
\text { drying (10 s); } 2 \text { - Application of } 2 \text { coats of the } \\
\text { primer(10 s with slight agitation); } 3 \text { - Air-drying } \\
\qquad(10 \mathrm{~s} \text { at } 20 \mathrm{~cm}) ; \\
4 \text { - Application of } 1 \text { coat of the adhesive (10 s } \\
\text { with slight agitation); } 5 \text { - Air-drying (10 s at } 20 \\
\left.\mathrm{~cm}) ; 6 \text { - Light-activation (10 s- } 600 \mathrm{~mW} / \mathrm{cm}^{2}\right)\end{array}$ \\
\hline $\begin{array}{l}\text { Adper Single Bond } \\
\qquad(2 \mathrm{GM})\end{array}$ & $\begin{array}{c}37 \% \text { phosphoric acid } \\
\text { Adhesive - Bis-GMA, HEMA, } \\
\text { dimethacrylates, polyalknoic acid } \\
\text { copolymer, initiators, water and ethanol }\end{array}$ & $\begin{array}{c}1 \text { - Acid etching (15 s), rinsing (15 s) and air- } \\
\text { drying }(10 \mathrm{~s}) ; \mathbf{2} \text { - Application of } 1 \text { coat of the } \\
\text { adhesive }(10 \mathrm{~s} \text { with slight agitation); } 3 \text { - Air-drying } \\
(10 \mathrm{~s} \text { at } 20 \mathrm{~cm}) ; \mathbf{4} \text { - Application of } 1 \text { coat of the } \\
\text { adhesive }(10 \mathrm{~s} \text { with slight agitation); } 5 \text { - Air-drying } \\
(10 \mathrm{~s} \text { at } 20 \mathrm{~cm}) ; 6 \text { - Light-activation (10 s - } 600 \\
\left.\mathrm{~mW} / \mathrm{cm}^{2}\right)\end{array}$ \\
\hline
\end{tabular}

Abbreviations: MDP (10-methacryloyloxydecyl dihydrogen phosphate); HEMA (2-hydroxyethyl methacrylate); Bis-GMA (bisphenol-glycidyl methacrylate); BPDM (biphenyl dimethacrylate); GDMA (glycidyl dimethacrylate)

FIGURE 1- Adhesive systems, composition and directions for using 
according to the following equation (values in $\mathrm{MPa}$ ): BSI:

$I_{t}=\left(B_{A / M} \times \%_{A / M}\right)+\left(C_{D} \times \%_{D}\right)+\left(C_{R} \times \%_{R}\right)+\left(B_{D S} \times \%_{D S}\right) / 100$

Where:

$B_{A / M}$ Mean bond strength of sticks with adhesive/mixed fracture pattern;

$\%_{A / M}$ Percentage of sticks with adhesive/mixed fracture pattern;

$C_{D}$ Cohesive strength of enamel;

$\%_{D}$ Percentage of sticks that failed cohesively in enamel;

$C_{R}$ Cohesive strength of resin;

$\%_{R}$ Percentage of sticks that failed cohesively in resin;

$B_{D S}$ Bond strength attributed to sticks that spontaneously debonded during preparation;

$\%_{\text {DS }}$ Percentage of sticks debonded during preparation.

The cohesive strength of the composite resin and the cohesive strength of enamel are considered as the mean value of all the specimens (from a single tooth) that failed in that manner. The mean value attributed to specimens that failed prematurely during preparation is arbitrary, and corresponded to approximately half of the minimum bond strength value that could be measured in this study. The microtensile BSIs were subjected to a two-way repeated measures analysis of variance and Tukey's post-hoc test $(\alpha=0.05)$ for pair-wise comparisons. The substrate treatment was the repeated factor.

\section{Enamel Etching Pattern}

The effect of conditioning with $35 \%$ phosphoric acid and the self-etching primers on ground and unground buccal or lingual enamel surfaces was analyzed. Enamel surfaces that were not treated with the conditioners and bur-cut and silicon carbide paper-treated surfaces were also observed for comparison purposes. Teeth $(n=2 /$ condition) were bisected longitudinally in a mesiodistal direction to provide two halves. A deep lingual guiding slit was prepared with a diamond bur to facilitate subsequent fracture of the etched surfaces. Free enamel surfaces were cleaned with pumice/ water slurry - prophylaxis (Group 1). After cleaning, the enamel surfaces from Group 2 were bur-cut and those from Group 3 were ground with wet 60 -grit silicon carbide paper for $60 \mathrm{~s}$, as described for the microtensile bond strength testing. Enamel surfaces from Groups 1, 2 and 3 were treated with $35 \%$ phosphoric acid and self-etching primers as described in Figure 1. Phosphoric acid-etched enamel was rinsed with water spray for $15 \mathrm{~s}$, while enamel etched with self-etching primers was rinsed with alternate baths of ethanol and acetone $(20 \mathrm{~s}$ each) in order to remove the monomers ${ }^{6}$. Thereafter, the same specimens were gently split with a hammer and scalpel blade along the pre-formed slits to provide a sagittal view of the etched enamel. Specimens were stored in a desiccator containing silica gel for $12 \mathrm{~h}$. Following that, they were mounted on aluminum stubs with colloidal silver and gold sputter-coated (Balzers SCD 050 Sputter Coater, Bal-Tec, Germany) to be observed under a scanning electron microscope (Philips XL30; Eindhoven, The Netherlands) at $15 \mathrm{kV}$ of accelerating voltage. Both the buccal and lingual etched surfaces as well as the sagittally fractured surfaces of the same tooth were examined.

\section{RESULTS}

\section{Microtensile Bond Strength}

The mean cross-sectional area ranged from $0.73 \pm 0.2$ $\mathrm{mm}^{2}$ and no difference was detected among the treatment groups $(\mathrm{p}>0.05)$. The mean BSIs $(\mathrm{MPa})$ and standard deviations, as well as the number of tested sticks and the number of prematurely debonded specimens are shown in Table 1. Neither the main factor surface treatment $(\mathrm{p}=0.48)$ nor the interaction adhesive $\mathrm{X}$ surface treatment were statistically significant $(\mathrm{p}=0.06)$. Significant differences were observed among the adhesive systems tested $(\mathrm{p}=0.0001)$. The highest resin-enamel mean bond strength value was observed for the two etch-and-rinse adhesive systems (SBMP and SB). OP, AD and TY showed the lowest resinenamel mean bond strength values, which were statistically different from all others adhesives. CSE showed the highest mean bond strength value among the self-etching adhesive systems (Table 2). The bond failures modes were predominantly of the mixed type.

\section{Enamel Etching Pattern}

Scanning electron microscopy (SEM) micrographs of

TABLE 1- Bond strength indexes in MPa (means \pm standard deviations). Number of tested sticks and prematurely debonded sticks "(n/n)"

\begin{tabular}{lrcc}
\hline Adhesive system & No preparation & SiC paper-treated enamel & Bur-treated enamel \\
\hline Clearfil SE Bond & $18.7 \pm 4.6(34 / 06)$ & $22.7 \pm 1.8(32 / 05)$ & $19.9 \pm 4.1(43 / 06)$ \\
OptiBond SOLO & $7.8 \pm 1.5(29 / 14)$ & $13.7 \pm 3.1(31 / 09)$ & $12.2 \pm 2.4(32 / 16)$ \\
Adhe SE & $9.4 \pm 1.3(44 / 20)$ & $12.1 \pm 1.5(38 / 13)$ & $12.25 .7(39 / 14)$ \\
Tyrian SPE & $10.9 \pm 3.2(33 / 12)$ & $12.8 \pm 1.6(38 / 10)$ & $9.6 \pm 4.2(48 / 19)$ \\
Adper SBMP Plus & $22.7 \pm 5.2(49 / 03)$ & $24.8 \pm 1.5(46 / 03)$ & $18.63 .3(36 / 05)$ \\
Adper Single Bond & $26.7 \pm 4.6(46 / 03)$ & $22.0 \pm 2.3(38 / 03)$ & $26.0 \pm 5.1(38 / 06)$ \\
\hline
\end{tabular}



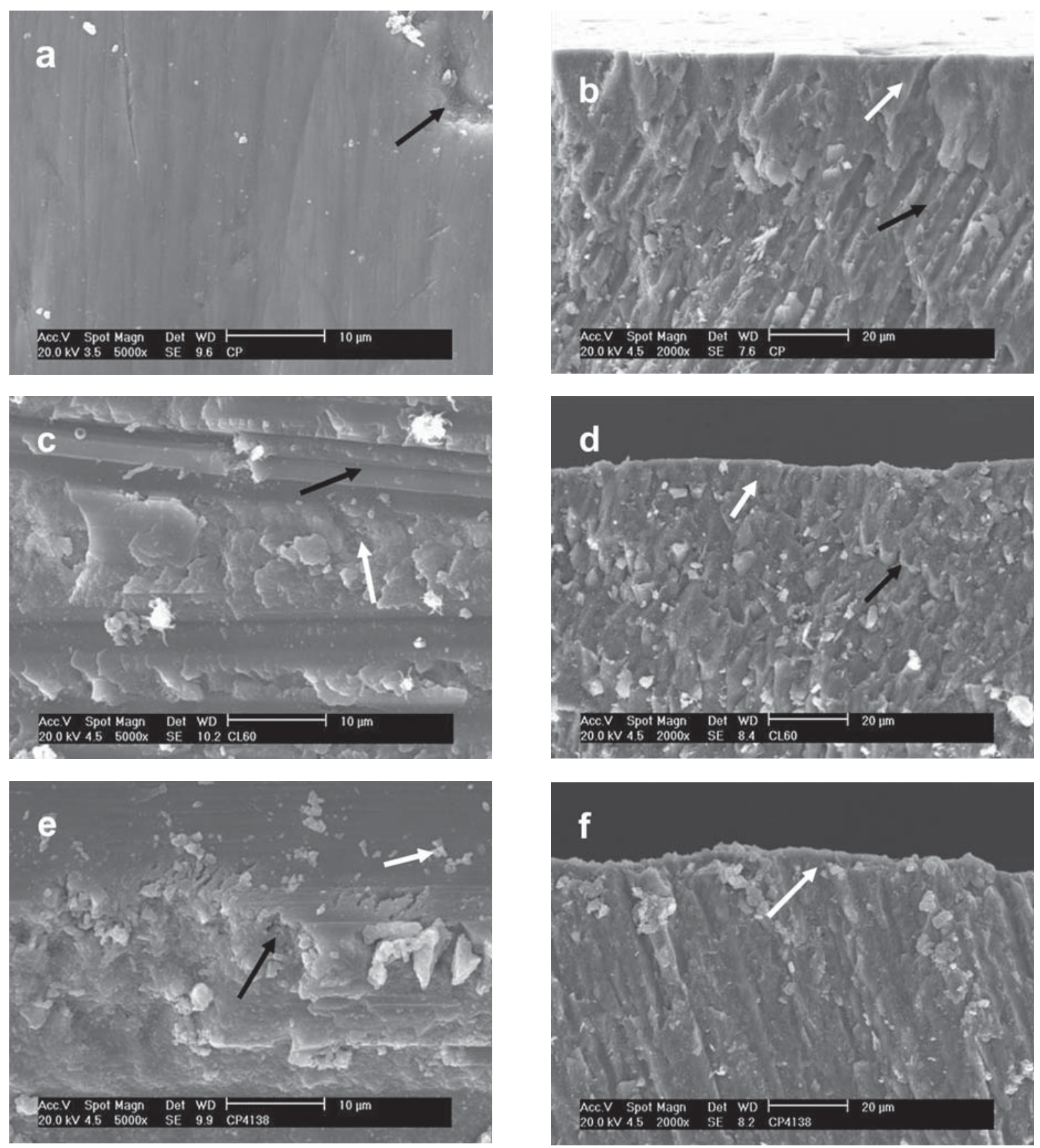

FIGURE 2- Effects of the different preparation methods on the enamel surface. a - The surface after prophylaxis is smooth with few enamel rods exposed (black arrow); b - Sagittal view of Figure a: prismless enamel (white arrow) and enamel rods (black arrow); c - The surface after SiC treatment is rough, with grooves (black arrow) and some exposed enamel rods (white arrow); d - Sagittal view of Figure c. Prismless enamel (white arrow) and enamel rods (black arrow); e - The surface after diamond bur treatment is very rough, with a thick smear layer (white arrow) and enamel rods (black arrow); $f$ - Sagittal view of Figure e. Enamel rods are reaching the surface (white arrow)

ground and unground enamel surfaces treated with phosphoric acid and the self-etching primers are shown in Figures 3 to 7 . The effect of prophylaxis, diamond bur or $\mathrm{SiC}$ paper treatments was also analyzed (Figure 2).

Enamel surface after prophylaxis was very smooth, with small and shallow grooves and few exposed enamel rods. An apparently rougher surface than that created by prophylaxis with more grooves could be seen after enamel grinding with 60-grit $\mathrm{SiC}$ paper. Diamond bur-prepared enamel showed larger and deeper grooves than those created 
TABLE 2- Bond strength indexes (MPa; means \pm standard deviations) for the tested adhesive systems regardless of the enamel treatment

\begin{tabular}{ll}
\hline Adhesive system & Bond Strength \\
\hline Clearfil SE Bond & $20.5 \pm 3.5 \mathrm{~b}$ \\
OptiBond SOLO & $11.3 \pm 2.3 \mathrm{c}$ \\
Adhe SE & $11.2 \pm 2.8 \mathrm{c}$ \\
Tyrian SPE & $11.1 \pm 3.0 \mathrm{c}$ \\
Adper SBMP Plus & $21.9 \pm 4.0 \mathrm{a}, \mathrm{b}$ \\
Adper Single Bond & $24.9 \pm 3.0 \mathrm{a}$ \\
\hline
\end{tabular}

by the other methods of preparation as well as an apparently rougher smear layer. Regardless of the surface treatment, only the diamond bur removed the prismless enamel (Figure 2). SEM micrographs of the enamel surfaces etched with $35 \%$ phosphoric acid revealed little difference among the methods of preparation (Figure 3). In all specimens, the smear layer was totally removed by phosphoric acid and enamel rods were exposed and etched. The selective etching of prism cores (Type 1 pattern) and prism peripheries (Type 2 pattern) along with areas without selective demineralization could be observed in the same specimen.

The enamel surfaces following treatment with CSE showed a predominant smooth surface with shallow depressions along the enamel surface (Figure 4). When mild self-etching primer was used on prepared surfaces, the smear layer appeared to be partially removed. The etching pattern created by the CSE primer was more evident on the intact enamel surface. The etching appearance of $\mathrm{AD}$ and $\mathrm{OP}$ presented similar morphological features (Figures 5 and 6 respectively). The $\mathrm{pH}$ of these moderate self-etching primers allowed them to remove the smear layer created by the $\mathrm{SiC}$ paper and by the diamond bur in a more effective way than the mild CSE primer. Areas of un-etched and smooth surfaces were intercalated with some deep and large grooves on enamel. The demineralization pattern of these systems was more pronounced when they were applied on the diamond bur-prepared surface, i.e., prismatic enamel surface.

Unlike the enamel microporosities produced by $35 \%$ phosphoric acid, the porosities produced by the most acidic self-etching primer, TY, were less numerous, deeper and larger (Figure 7). It was also evident the presence of fine surface roughening on the enamel surface with an uneven conditioning pattern. Regardless of the preparation method and the $\mathrm{pH}$ of the primer, none of the evaluated self-etching primers was able to expose the enamel rods as did the $35 \%$ phosphoric acid.
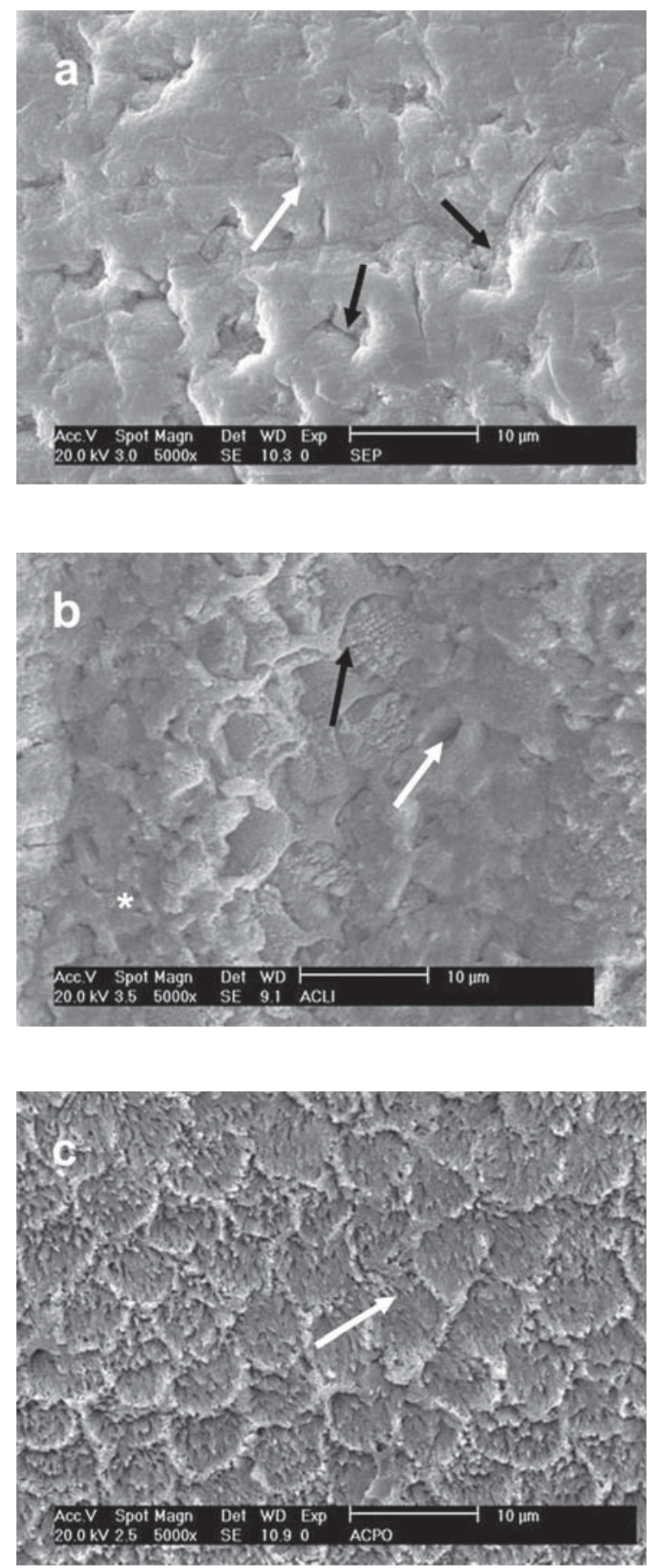

FIGURE 3- Effects of 35\% phosphoric acid etching on the different enamel-prepared surfaces. a - Prophylaxis: Areas of specific enamel etching pattern (white arrow - type 1 pattern; black arrow - type 2 pattern); b - SiC paper: The same morphological findings of Figure a, emphasizing the areas with a non-uniform etching pattern (white asterisk); c - Diamond bur: Type I etching pattern (white arrow) is predominantly seen 

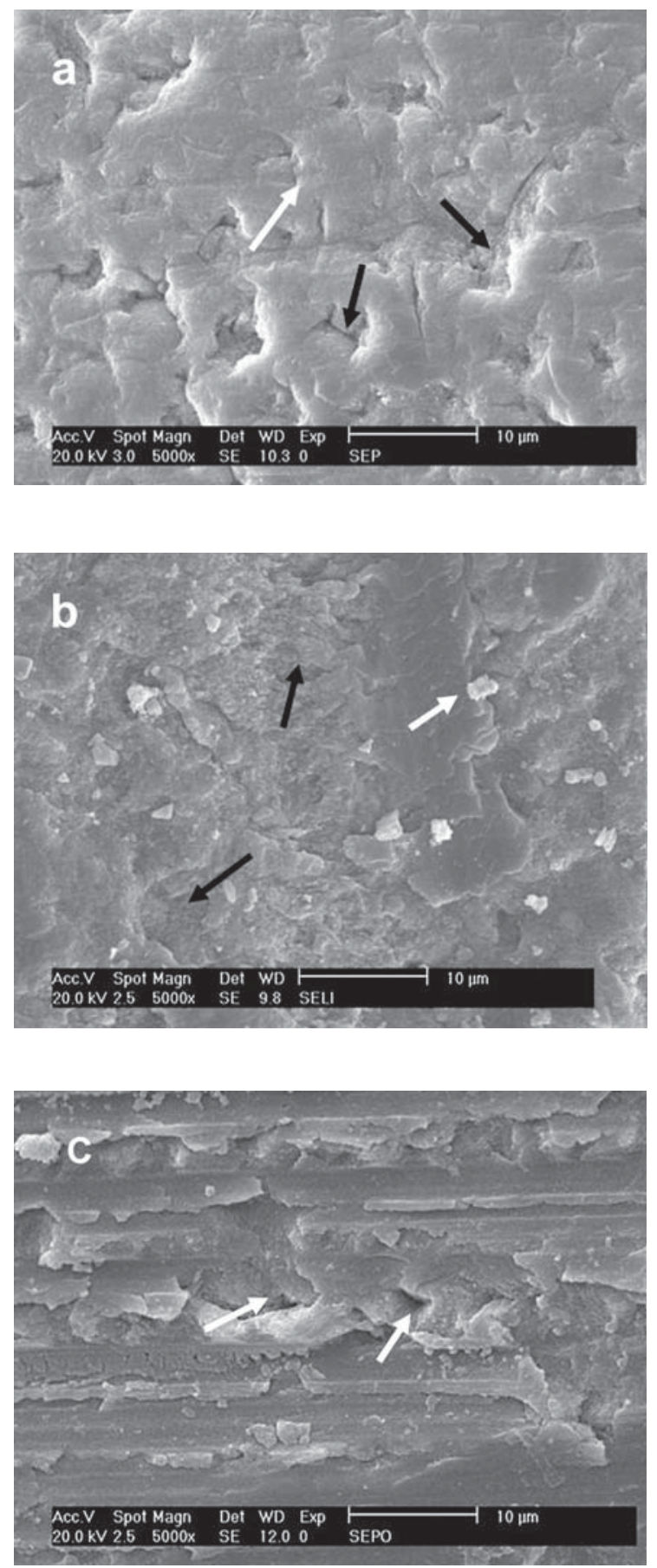

FIGURE 4- SEM micrograph of different enamel treatedgroups following treatment with Clearfil SE primer. a Prophylaxis: Small grooves (white arrow) and shallow depressions (black arrow) were seen in a predominantly flat surface; $b$ - SiC paper: The white arrow shows smear layer remnants and the black arrow points to shallow depressions; c - Diamond bur: The CSE primer did not enhance the roughness provided by the diamond bur. Shallow depressions were observed (white arrows)
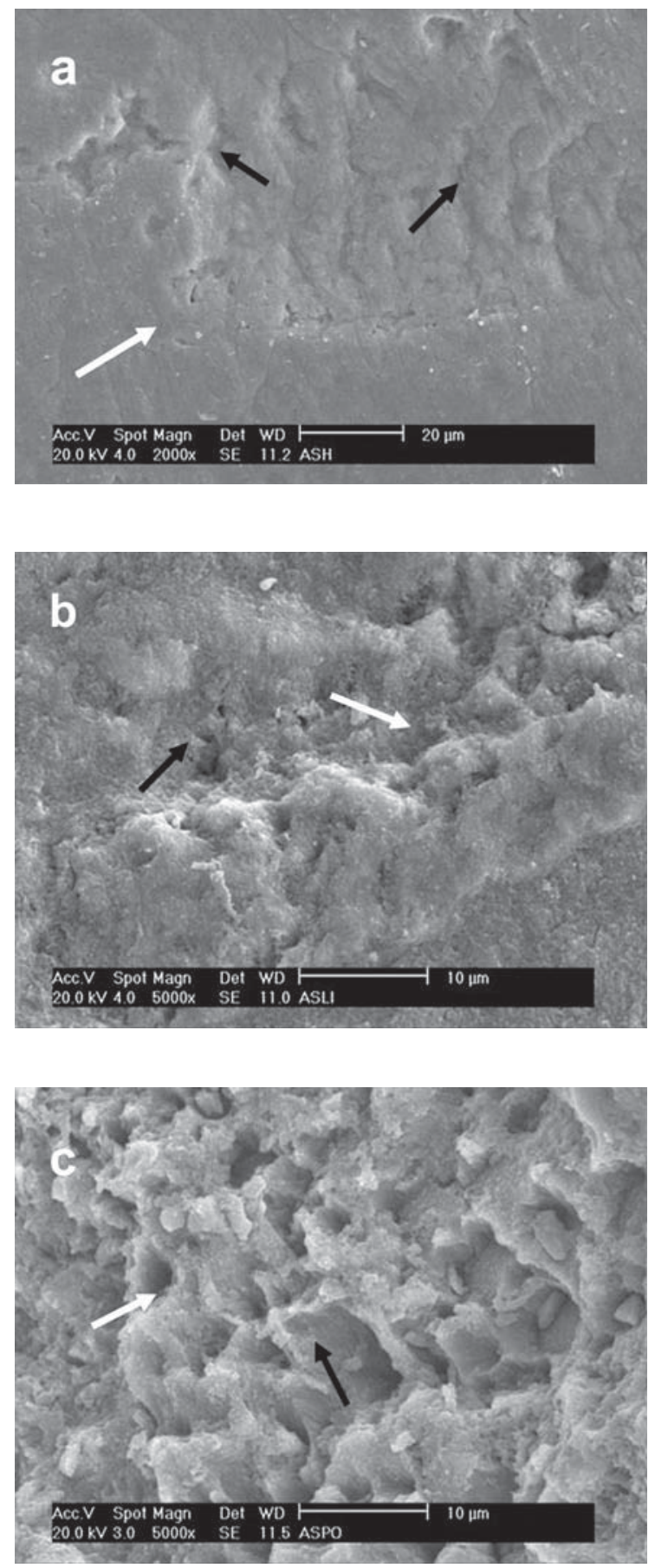

FIGURE 5- SEM micrograph of different enamel treatedgroups following treatment with AdheSe self-etching primer. a - Prophylaxis: The surface is predominantly smooth (white arrow) with areas of shallow and wide depressions (black arrow); $b$ - SiC paper: The demineralization pattern is not uniform (black arrow). Areas with deep and narrow depressions can be seen (white arrow); c - Diamond bur: Enamel rods (black arrow) and a Type I etching pattern (white arrow) can be identified 

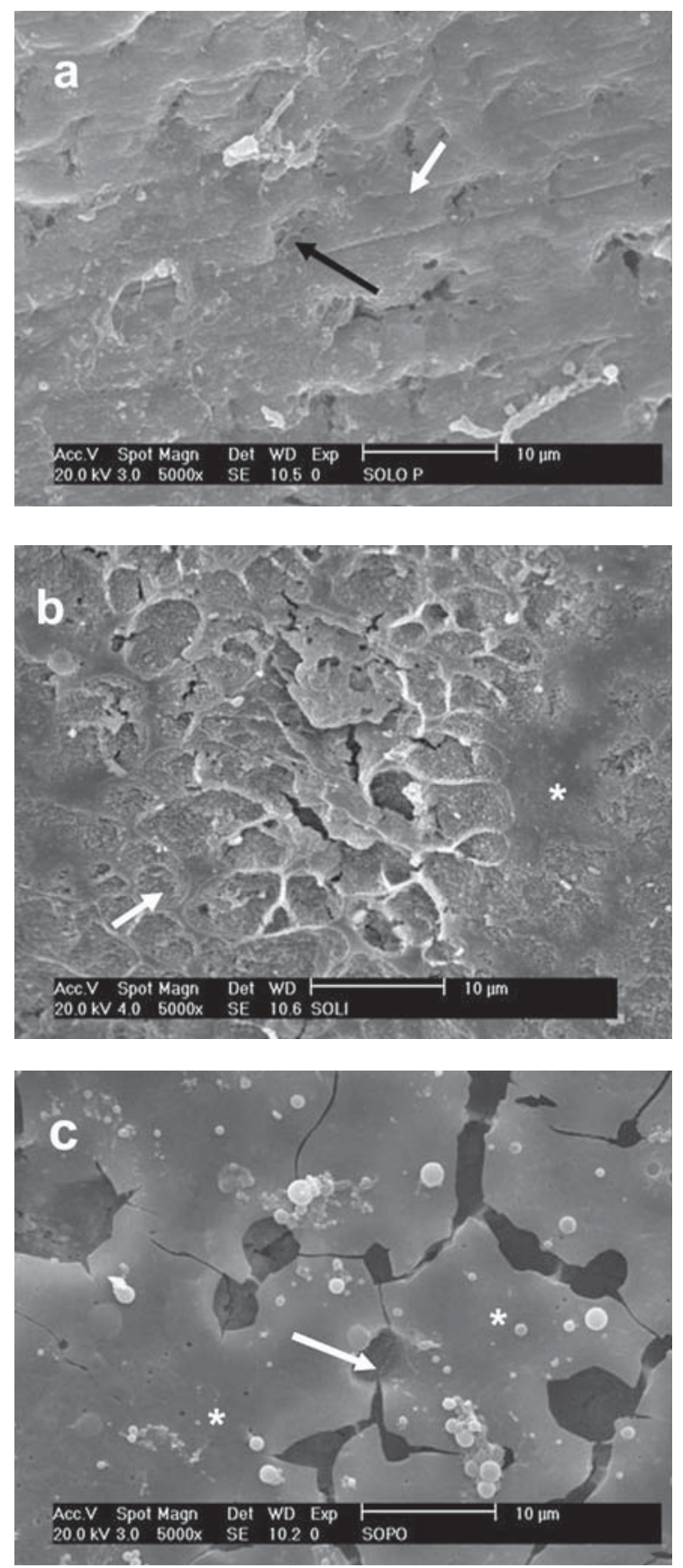

FIGURE 6- SEM micrograph of different enamel treatedgroups following treatment with OptiBond Self-etching primer. a - Prophylaxis: Small grooves (white arrow) can be identified. Shallow depressions are presented in a predominantly flat surface (black arrow); b - SiC treatment: Shallow-wide depressions (white arrow) and unetched areas (white asterisk) are predominant. Narrow and deep depressions (black arrow) are dispersed within shallow demineralized areas; c - Diamond bur: Note a cracked smooth surface (white asterisk) with remaining self-etching primer and deep and wide depressions (white arrow) showing the effect of the self-etching primer on the treated enamel surface
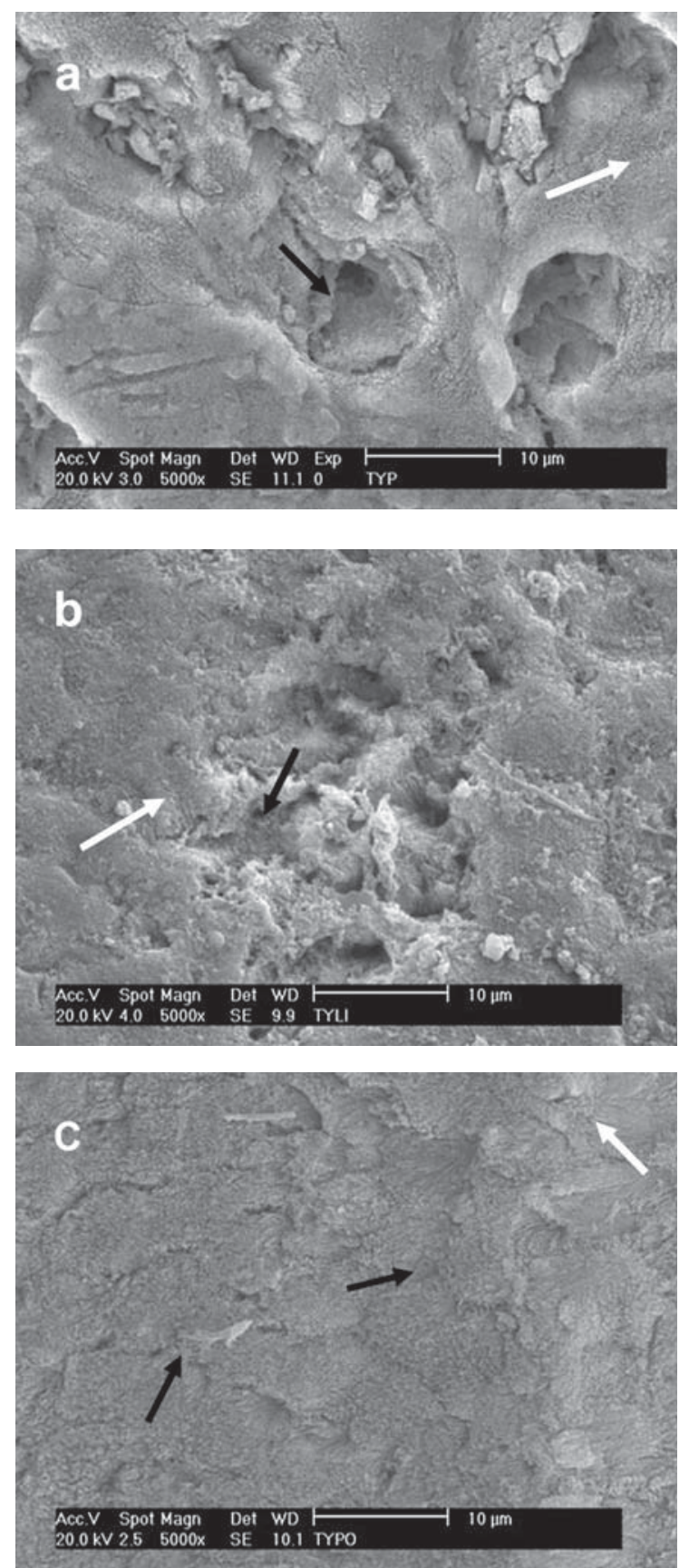

FIGURE 7- SEM micrograph of different enamel treatedgroups following treatment with Tyrian SPE. a - Prophylaxis: Deep and wide holes (black arrow) along with a fine roughening (white arrow); $b$ - SiC treatment: The fine surface roughening (white arrow) along with shallow depressions (black arrow); c - diamond bur: Note the fine surface roughening (white arrow) along with enamel rods (black arrow) 


\section{DISCUSSION}

The null hypothesis was not totally accepted because the bond strength and the morphology of surface enamel varied depending on the adhesive system.

The morphological structure of the intact peripheral enamel surface is different from that of the middle and inner enamel layer. It has been widely reported that the superficial layer of enamel is less reactive to acids than the middle layer. As the acidity of the self-etching adhesive systems are relatively lower than that of phosphoric acid treatment, the presence of this superficial enamel layer has been partially blamed for the lower performance of the self-etching systems in this substrate $3,11,13,15,16$.

This study demonstrated that the 0.5 -mm-deep grinding produced by the diamond bur was the only treatment able to homogeneously remove the prismless enamel. Pumice prophylaxis and $\mathrm{SiC}$ paper abrasion did not remove this layer. Despite these morphological results, it was impossible to distinguish under SEM differences in the surface micromorphology of ground ( $\mathrm{SiC}$ paper and diamond bur) and unground enamel after conditioning with phosphoric acid, since all treatments depicted the presence of enamel rods. This may be one of the reasons why differences between enamel surface preparations were not found in the phosphoric acid group. This finding is in accordance with other studies that evaluated the performance of etch-andrinse adhesives on ground and unground enamel ${ }^{10,13,22,27}$.

When the morphological findings of the same adhesive system were compared on ground and unground enamel some differences in the etching pattern were observed. The two moderate (OP and AD) and the most acidic (TY) selfetching systems demineralized the ground enamel surface more effectively than the intact enamel. Despite these variations, enamel surface preparation showed no significant effect on the bond strength values. The literature in this matter is controversial. Some studies have demonstrated that enamel abrasion with diamond burs can improve the bond strength of self-etching systems to enamel ${ }^{13,27}$. Other studies, in agreement with the present findings, have observed that the bond strength to unground or ground enamel does not differ ${ }^{7,10}$ or it is dependent on the adhesive system evaluated $^{22}$.

This apparent controversy means that the lower performance of self-etching adhesive systems on enamel ${ }^{3,11,13,15,16}$ cannot be solely attributed to the presence of the prismless enamel. Other factors apart from substraterelated issues could be responsible for such differences. Variation in adhesive viscosity, surface tension, acidity of the self-etch system, chemical interaction of acidic monomers with enamel ${ }^{34}$, water concentration ${ }^{9}$, cohesive strength of the adhesives ${ }^{24,28}$ are important features to be considered. This is somewhat true that although a more retentive etching pattern was observed for the moderate (OP and AD) and particularly for the most acidic (TY) adhesives in comparison to the mild CSE, higher bond strength values were not observed for TY. The TY adhesive applied on diamond bur-prepared enamel produced an etching pattern that resembled that of $35 \%$ phosphoric acid etching, although the delineation of enamel rods was not as evident as that created by phosphoric acid.

Contrary to these findings, other studies have demonstrated that more acidic self-etching systems were able to produce an extremely defined pattern of enamel etching, similar to phosphoric acid conditioning ${ }^{1,8}$ even when applied on intact enamel surface ${ }^{21}$. It is likely that differences in the composition of adhesive systems employed in these studies could have played a role on this apparent controversy. In addition to the concentration and the type of acidic monomers that directly alter the acidity of self-etching adhesive systems ${ }^{18}$, differences in the water concentration among in the systems can also contribute to partial or total dissociation of the acid functionalities ${ }^{18}$. It has been demonstrated that increasing water concentration from 10 to $20 \mathrm{vol} \%$ resulted in an increase in the degree of ionization of an acidic monomer, lowering the $\mathrm{pH}$ of the self-etching primer solution and further increasing their depth of demineralization?.

SEM examination of the surface morphology of enamel has shown that CSE produced a very mild etching effect ${ }^{8}$, with the bulk of the surface remaining unetched. This means that among the adhesive systems tested in the present study, CSE has only superficial interaction with enamel and a reduced potential for micromechanical interlocking. Despite these morphological findings, CSE achieved the highest bond strength values among the self-etching adhesive systems. Indeed, this finding is in accordance with previous studies, which demonstrated that mild self-etching adhesive systems perform well when compared to more acidic systems either in intact enamel or dentin ${ }^{4,11,12,15}$

It is clear from the micromorphological findings of this study that the use of a stronger acid resulted in a more dramatic dissolution and a more defined etching pattern, as previously reported ${ }^{21}$. However this fact did not translate entirely into higher bond strengths. Low bond strength values are usually reported for more acidic self-etching adhesive systems when they are compared under microtensile bond strength approach ${ }^{4,11,31}$.

The absence of relationship between the depth of demineralization and the strength of bonds produced by the more aggressive self-etching and etch-and-rinse adhesive systems on enamel shown in the present investigation is consistent with previous works ${ }^{10,21,29}$. As already reported, this means that other factors, apart from the etching pattern, may have a more important role on the bond strength values. For instance, CSE is a self-etching primer that contains 10methacryloxydecyl dihydrogen phosphate (10-MDP) as functional monomer dissolved in water to result in a $\mathrm{pH}$ of around 2. The excellent performance of this system in vitro ${ }^{4,12,15}$ and in vivo investigations ${ }^{32}$ may be partially attributed to the additional chemical interaction of hydroxyapatite with the functional monomer $10-\mathrm{MDP}^{34}$. This can theoretically contribute to the actual adhesive potential to enamel that consists of nearly only mineral substance, with which 10-MDP can chemically react.

Pashley, et al. ${ }^{20}$, using a modeling approach, 
demonstrated that the theoretical strength of the resin-dentin bond strength should be proportional to the strength of the adhesive used to infiltrate demineralized dentin. This was also confirmed in some laboratorial studies ${ }^{24,28}$. When bonding to dentin, a strong relationship between the resindentin bond strengths and the mechanical properties of cured resin was observed for the self-etching adhesive systems ${ }^{24}$.

The high initial $\mathrm{pH}$ of more acidic systems appear to dramatically weaken the bonding performance, either via chemical interacting with the adhesive layer placed next ${ }^{26}$ or via the presence of solvents within the polymer, which render the adhesive layer thinner and may weaken the polymer formed ${ }^{2}$, thus compromising their bond strength to enamel. As the acidity of self-etching adhesives is increased with the incorporation of higher concentration of hydrophilic and acidic monomers, the problems that are associated with acid-base incompatibility and water permeability become even more accentuated. The acidic components of these adhesives may also adversely interact with the composite's photoinitiator and so weaken the bonding complex ${ }^{2,6}$.

Another point to be considered is the reported low hydrolytic stability of methacrylates in acidic solutions ${ }^{17,19}$. According to some authors ${ }^{17,19}$, the ester portion of functional methacrylate, such as HEMA, used for a self-etching primer can become hydrolyzed in aqueous solutions when the $\mathrm{pH}$ values were below 2 . They also suggested that the hydrolysis rate of the ester portion of methacrylates is also dependent on the storage temperature, which means that the self-etching primer should be kept refrigerated when not in use. Although phosphorus-containing monomers, such as MDP, are said to be more stable in acid environment, they should also be kept refrigerated when not in use.

\section{CONCLUSION}

In summary, it may be concluded that preparation of enamel surface (prophylaxis, diamond bur or SiC-paper) did not influence the bonding performance of the self-etching adhesive systems evaluated in this study. The highest bond strength values were observed for the etch-and-rinse adhesive systems.

\section{ACKNOWLEDGEMENTS}

The authors are grateful to The State of São Paulo Research Foundation/FAPESP (Grants 03/10416-8 and 03/ 12192-0) for financial support.

\section{REFERENCES}

1- Breschi L, Gorbi P, Falconi M, Mazzotti G, Prati C, Perdigão J. Ultramorphology of self-etching adhesives on ground enamel: a high resolution SEM study. Am J Dent. 2003;16:57A-62A.

2- Cho BH, Dickers SH. Effects of the acetone content of single solution dentin bonding agents on the adhesive agents on the adhesive layer thickness and the microtensile bond strength. Dent Mater. 2004;20:107-15.
3- De Munck J, Van Landuyt K, Peumans M, Poitevin A, Lambrechts P, Braem M, et al. A critical review of the durability of adhesion to tooth tissue: methods and results. J Dent Res. 2005;84:118-32.

4- De Munck J, Van Meerbeek BV, Satoshi I, Vargas M, Yoshida Y, Armstrong S, et al. Microtensile bond strengths of one- and two-step selfetch adhesives to bur-cut enamel and dentin. Am J Dent. 2003;6:414-20.

5- De Wald JP. The use of extracted teeth for in vitro bonding studies: a review of infection control considerations. Dent Mater. 1997;13:74-81.

6- Di Hipólito V, de Goes MF, Carrilho MR, Chan DC, Daronch M, Sinhoreti MA. SEM evaluation of contemporary self-etching primers applied to ground and unground enamel. J Adhes Dent. 2005;7:203-11.

7- Dias WR, Pereira PNR, Swift EJ Jr. Effect of surface preparation on microtensile bond strength of three adhesive systems to bovine enamel. J Adhes Dent. 2004;6:279-85.

8- Hashimoto M, Ohno H, Yoshida E, Hori M, Sano H, Kaga M, et al. Resin enamel bonds made with self-etching primers on ground enamel. Eur J Oral Sci. 2003;111:447-53.

9- Hiraishi N, Nishiyama N, Ikemura K, Yau JYY, King NM, Tagami J, et al. Water concentration in self-etching primers affects their aggressiveness and bonding efficacy to dentin. J Dent Res. 2005;84:653-8.

10- Ibarra G, Vargas MA, Armstrong SR, Cobb DS. Microtensile bond strength of self-etching adhesives to ground and unground enamel. J Adhes Dent. 2002;4:115-24

11- Inoue S, Vargas MA, Abe Y, Yoshida Y, Lambrechts P, Vanherle G, et al. Microtensile bond strength of eleven contemporary adhesives to enamel. Am J Dent. 2003;16:329-34.

12- Kaaden C, Powers JM, Friedl KH, Schmalz G. Bond strength of selfetching adhesives to dental hard tissues. Clin Oral Investig. 2002;6:15560 .

13- Kanemura N, Sano H, Tagami J. Tensile bond strength to and SEM evaluation of ground and intact enamel surfaces. J Dent. 1999;27:523-30.

14- Kenshima S, Reis A, Uceda-Gomez N, Tancredo LLF, Rodrigues LE Filho, Nogueira FN, et al. Effect of smear layer thickness and $\mathrm{pH}$ of selfetching adhesive systems on bond strength and gap formation. J Adhes Dent. 2005;7:117-26.

15- Lopes GC, Marson FC, Vieira LCC, Andrada MAC, Baratieri LN Composite bond strength to enamel with self-etching primers. Oper Dent. 2004;29:424-9.

16- Miguez PA, Castro PS, Nunes MF, Walter R, Pereira PNR. Effect of acid-etching on the enamel bond of two self-etching systems. J Adhes Dent. 2003;5:107-12.

17- Moszner N, Salz U, Zimmermann J. Chemical aspects of self-etching enamel-dentin adhesives: a systematic review. Dent Mater. 2005;21:895910 .

18- Nishiyama N, Suzuki K, Takahashi K, Nemoto K. The pka effects of the carboxylic acid in $\mathrm{N}$-methacryloxyl-omega-amino acid on the demineralization and bond strengths to the teeth. Biomaterials. 2004:25:5441-7.

19- Nishiyama N, Suzuki K, Yoshida H, Teshima H, Nemoto K. Hydrolytic stability of methacrylamide in acidic aqueous solution. Biomaterials. $2004 ; 25: 965-9$

20- Pashley DH, Ciucchi B, Sano H, Carvalho RM, Russell CM. Bond strength versus dentine structure: a modeling approach. Arch Oral Biol. 1995;40:1109-18. 
21- Pashley DH, Tay FR. Aggressiveness of contemporary self-etching adhesives. Part II: etching effects on unground enamel. Dent Mater. 2001;17:430-44.

22- Perdigão J, Gomes G, Duarte S Jr, Lopes MM. Enamel bond strengths of pairs of adhesives from the same manufacturer. Oper Dent. 2005;30:4929.

23- Peumans M, Kanumilli P, De Munck J, Van Landuyt K, Lambrechts P, Van Meerbeek B. Clinical effectiveness of contemporary adhesives: a systematic review of current clinical trials. Dent Mater. 2005;21:864-81.

24- Reis A, Grandi V, Carlotto L, Bortoli G, Patzlaff RT, Accorinte MLR, et al. Effect of smear layer thickness and acidity of self-etching solutions on early and long-term bond strength to dentin. J Dent. 2005;33:549-59.

25- Reis A, Loguercio AD, Azevedo CL, Carvalho RM, Singer JM, Grande RHM. Moisture spectrum of demineralized dentin for adhesive systems with different solvent bases. J Adhes Dent. 2003;5:183-92.

26- Sanares AM, King NM, Ittagarun A, Tay FR, Pashley DH. Adverse surface interactions between one-bottle light-cured adhesives and chemicalcured composites. Dent Mater. 2001;17:542-56.

27- Senawongse P, Sattabanasuk V, Shimada Y, Otsuki M, Tagami J. Bond strengths of current adhesive systems on intact and ground enamel. J Esthet Restor Dent. 2004;16:107-16.

28- Takahashi A, Sato Y, Uno S, Pereira PNR, Sano H. Effects of mechanical properties of adhesive resins on bond strength to dentin. Dent Mater. 2002;18:263-8.

29- Tay FR, Pashley DH, King NM, Carvalho RM, Tsai J, Lai SCN, et al. Aggressiveness of self-etch adhesives on unground enamel. Oper Dent. 2004;29:309-16.

30- Tay FR, Pashley DH. Aggressiveness of contemporary self-etching systems. I: depth of penetration beyond dentin smear layers. Dent Mater. 2001; 17:296-308

31- Van Meerbeek B, De Munck J, Mattar D, Van Landuyt K, Lambrechts P. Microtensile bond strength of an etch \& rinse and self-etch adhesive to enamel and dentin as a function of surface treatment. Oper Dent. 2003;28:647-60.

32- Van Meerbeek B, Kanumilli P, De Munck J, Landuyt KV, Lambrechts P, Peumans M. A randomized controlled study evaluating the effectiveness of a two-step self-etch adhesive with and without selective phosphoric-acid etching of enamel. Dent Mater. 2005;21:375-83.

33- Van Meerbeek B, Perdigão J, Lambrechts P, Venherle G. The clinical performance of adhesives. J Dent. 1998;26:1-20.

34- Yoshida Y, Nagakane K, Fukuda R, Nakayama Y, Okazaki M, Shintani $\mathrm{H}$, et al. Comparative study on the adhesive performance of functional onomers. J Dent Res. 2004;83:454-8. 